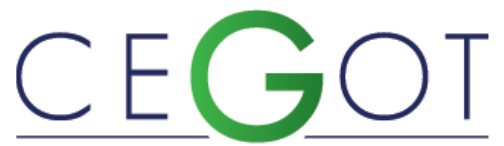

Centro de Estudos de Geografia e Ordenamento do Território
Geografia e Ordenamento do Território, Revista Eletrónica Centro de Estudos de Geografia e Ordenamento do Território http://cegot.org

TAVARES, FeliPE

Pontifícia Universidade Católica do Rio de Janeiro, Departamento de Geografia e Meio Ambiente Rua Marquês de São Vicente, 225, sala 411F, 22453-900, Rio de Janeiro, Brasil tavares.geo@gmail.com

\title{
Metropolização do espaço e biopolítica: território, in-segurança e reconfiguração do Estado
}

Metropolization of space and biopolitics: territory, in-security and State reconfiguration

Referência: Tavares, Felipe (2018). Metropolização do espaço e biopolítica: território, in-segurança e reconfiguração do Estado. Revista de Geografia e Ordenamento do Território (GOT), n. ${ }^{\circ} 15$ (dezembro). Centro de Estudos de Geografia e Ordenamento do Território, p. 429-451, dx.doi.org/10.17127/got/2018.15.018

\section{RESUMO}

Enfatizando as dimensões do comando, do controle e do domínio no âmbito dos fenômenos que reconfiguram o papel do Estado, a saber, as problemáticas ligadas à in-segurança, risco e des-controle, focalizamos o processo de metropolização do espaço a partir de sua manifestação biopolítica: aquela que diz respeito à circulação da população no território e à regulação da des-ordem, constituindo objeto de pesquisa sobre o qual dirigimos a atenção neste artigo. Discutimos a relação entre metropolização e biopolítica a fim de verificar a emergência de um modo de gestão da vida coletiva num espaço constituído na dispersão, na fluidez e por redes, revelando a des-re-territorialização do Estado, sobretudo pela emergência de tecnologias e dispositivos de segurança que reestruturam o espaço, promovendo, simultaneamente, a coesão do território e a coerção da população.

Palavras-chave: metropolização, biopolítica, território, segurança, Estado, Rio de Janeiro.

\section{ABSTRACT}

Emphasizing the dimensions of command, control and domination in the context of the phenomena that reconfigure the role of the State, namely the problems related to insecurity, risk and dis-control, we focus the process of metropolization of space from its biopolitical manifestation: the one that concerns the movement of the population in the territory and the regulation of the dis-order, constituting object of research on which we direct the attention in this article. We discuss the relationship between metropolization and biopolitics in order to verify the emergence of a way of managing collective life in a space constituted by dispersion, fluidity and networks, revealing the de-re-territorialization of the State, especially by the emergence of technologies and devices that restructure the territory, while promoting territorial cohesion and population coercion.

Key-words: metropolization, biopolitics, territory, security, State, Rio de Janeiro. 


\section{Introdução}

A problemática da segurança, dos riscos e do medo emerge de tal forma, nos dias atuais, que sua força tem sido capaz de reestruturar territórios e relações sociais, implicando em novos arranjos espaciais e políticas de ordenamento territorial. Debruçar-se sobre tais questões tendo a metrópole como prisma é fundamental numa sociedade completamente urbana. Refletir acerca do papel do Estado, cujas prerrogativas clássicas são colocadas em xeque diante da internacionalização do capital, dos oligopólios transnacionais e do surgimento de instituições supranacionais (Banco Mundial, Fundo Monetário Internacional e a Organização das Nações Unidas), é crucial para compreender as tramas do poder e suas repercussões políticas na espacialidade, principalmente diante da ofensiva neoliberal sob a égide do capital financeiro. Deste modo, ao abordamos o tema da metropolização, tratamos de um processo espacial, focalizado a partir das relações de poder, aqui compreendidas pela biopolítica e pela in-segurança nos processos de estatização, como apresentaremos nas linhas que seguirão.

Temos o intuito de ressaltar e dar ênfase às relações de dominação e controle do espaço, ou seja, espacializações (e condições) de comando, privilegiando a dimensão da hierarquização (elemento de uma tríade formada pela homogeneização e fragmentação), a fim de evidenciar as determinações e condições espaciais no âmbito do processo de metropolização. A dimensão da hierarquização permite focalizar tais relações no âmbito da biopolítica e da segurança. Considerando o processo de metropolização, a hierarquização constitui o domínio do poder e do comando, "que são instrumentais para garantir a totalidade do conjunto" (Lencioni, 2010). As hierarquias exprimem no espaço o cotidiano programado e instauram o controle das práticas, a disciplina, a vigilância e o monitoramento. Constroem espaços que, nas palavras de Milton Santos (2006), são uma estrutura de controle e limite às ações. Como veremos, a partir da noção de "Meio" (Foucault, 2008), tratamos simultaneamente da problemática do (bio)poder (in-segurança, controle e comando) e da circulação (de bens, e principalmente, da população), questão crucial à compreensão da relação entre metropolização, reconfiguração do Estado e des-reterritorialização, que constitui o objeto de estudo em discussão. Portanto, nosso objetivo é analisar a dimensão biopolítica do processo de metropolização a partir da atuação do Estado no âmbito da problemática da circulação da população do território, isto é, da in- 
segurança, que faz emergir políticas de ordenamento territorial que lançam mão de tecnologias e dispositivos de vigilância, controle e monitoramento ${ }^{1}$.

Na primeira parte discutimos a relação entre metropolização e biopolítica a fim de verificar a emergência de um modo de gestão da vida coletiva num espaço constituído na dispersão, na fluidez e por redes. Na segunda parte, aprofundamos a análise ao refletir sobre a reconfiguração do papel do Estado, observada enquanto des-re-territorialização, no sentido das principais demandas contemporâneas que suscitam processos de estatização. Na última parte, denominada "a espacialidade da biopolítica no ordenamento do território", lançamos o olhar sobre os fluxos, a integração e o processo de hierarquização, levando em conta o surgimento de tecnologias/dispositivos informacionais de segurança que (re)estruturam o espaço metropolitano sob uma lógica reticular, concluindo que tais mecanismos promovem a coesão e, sobretudo, a coerção da população e do território.

\section{A metropolização do espaço equanto processo biopolítico}

A reflexão que se atem às determinações históricas que condicionam a sociedade e o espaço urbano contemporâneos deverá considerar as metamorfoses que reconfiguram a experiência do espaço-tempo. Se na década de 1960 alguns autores já percebiam uma fase crítica do urbano, caracterizada pela implosão-explosão da cidade, uma espécie de "urbanização planetária" que culminaria com a constituição de uma sociedade totalmente urbana, devemos reconhecer que, no presente, não se trata mais de desenvolver cidades, mas, de desenvolver condições que assegurem a gestão, reprodução e viabilização política do capital em âmbito transnacional, como afirma Lencioni (2006). Mesmo que os olhares sobre a urbanização planetária e a constituição de megalópoles sejam crucias para compreendermos o substrato desse novo processo, denominado metropolização - isto é, a

\footnotetext{
${ }^{1}$ A problemática da in-segurança, da violência, dos riscos e do medo exige um olhar crítico, sobretudo, porque as políticas públicas de ordenamento/planejamento territorial urbano empreendidas pelo Estado, em parceria com atores da iniciativa privada, na região metropolitana do Rio de Janeiro, revelam-se inadequadas, violadoras de direitos humanos e de enorme custo social e econômico. Neste artigo, a maior crítica dirige-se ao modo pelo qual o Estado concebe a população - como espécie biológica ligada à materialidade onde vivem, portanto, destituídos de cidadania, direitos e politicamente desqualificados. As políticas de ordenamento do território no âmbito da segurança pública atentam contra a dignidade humana de moradores de favelas e das periferias. Destarte, torna-se necessário questionar tais medidas de segurança, no intuito de desvelar suas dinâmicas e repensar alternativas para o tema, baseadas na participação popular e na democracia verdadeira.
} 
reestruturação produtiva e a globalização - outras dinâmicas tornam-se preeminentes, adquirem primazia diante da urbanização clássica. Neste sentido, ao falarmos num processo de metropolização, concordamos com os trabalhos de Lencioni (2017) que verifica a metropolização como um processo espacial que imprime características metropolitanas no espaço, metamorfoseando-o e adquirindo hegemonia em relação ao processo de urbanização, podendo também ser considerado como uma pós-urbanização.

Embora a metropolização desconheça vontades políticas, como afirma Lencioni (2006) ao atentar para a distinção necessária entre o processo espacial e a institucionalização das regiões metropolitanas (como expediente para o planejamento territorial), consideramos o processo de metropolização do espaço enquanto processo político e, portanto, constituído de relações de poder. Para a autora, a institucionalização das regiões metropolitanas consiste numa vontade política, que, segundo Souza (2006), seguiu à margem de todas as reflexões sobre a política urbana brasileira e, até então, à margem das políticas territoriais. Neste sentido, não se deve confundir o processo de metropolização com a institucionalização das regiões metropolitanas. Entretanto, também não se deve negligenciar a dimensão política de tais processos, neste caso, a vontade política que caracteriza a institucionalização das regiões metropolitanas a partir da década de 1970 no Brasil, como também a metropolização como processo político para além do poder institucional do Estado como forma de organização político-territorial. De acordo com Souza (2006), por meio das políticas, as regiões metropolitanas contribuíram para o elo da lógica capitalista: as prioridades governamentais se alinham conforme os interesses dos grandes agentes econômicos. A metropolização é um processo político.

Concordamos com Lefebvre (2008) em suas reflexões acerca da política e do espaço e, a partir de sua teoria do espaço social como produto social, podemos focalizar a dimensão política, inerente ao processo de metropolização. De acordo com o filósofo, a problemática do espaço é a do espaço vivido, aquele vinculado à prática social, portanto, diferentemente do espaço epistemológico - puro, vazio, lugar de números e proporções - o espaço social nunca é neutro (Lefebvre, p.40, 2008). O autor aborda o espaço como um intermediário, um "modo nas mãos de alguém" e "instrumento político intencionalmente manipulado", mesmo quando concebido enquanto neutro, "o espaço é povoado segundo os decretos do poder" (idem, p.45). Sendo assim, para Lefebvre, o espaço sempre foi político, ideológico e 
estratégico: "o espaço é politizado porque está inserido em estratégias conscientes ou inconscientes" (idem, p.67). Sendo assim, questionamos: no âmbito da metropolização do espaço, que estratégias são essas que determinam o caráter político do processo? A resposta reside no desenvolvimento de condições metropolitanas imprescindíveis para a reprodução do capital, uma determinação do momento histórico contemporâneo (Lencioni, p.48-49, 2006).

Ao apresentar alguns pontos comuns característicos de uma metrópole, Lencioni (2006, p.45) destaca: a concentração de serviços privados e públicos; a metrópole enquanto um ponto de grande densidade de emissão e recepção dos fluxos de bens, serviços, pessoas, informação e comunicação; a metrópole enquanto um nó significativo de redes (transporte, informação, comunicação, cultura, inovação, consumo, poder e cidades). A concentração de serviços, os fluxos permanentes e as redes aparecem como elementos determinantes do processo de metropolização, do momento histórico contemporâneo. A concentração de serviços de ordem superior expressa a função de direção e comando dos centros: são aqueles voltados para administração e gestão do capital das grandes empresas, também relativos ao setor financeiro e aqueles relativos à esfera pública - como os da administração pública e os relacionados ao controle político; uma necessidade e condição para garantir a gestão da reprodução do capital (idem, p.46). As redes e os fluxos se referem aos novos arranjos e dinâmicas territoriais que emergem das novas formas de organização da produção e da circulação (Lencioni, p.69, 2006b), expressando estratégias que buscam satisfazer a necessidade que o capital tem de abreviar o tempo total de rotação do capital (Lencioni, 2010).

Quando abordamos a questão da organização e controle do território, a partir da emergência de centros de poder, direção e comando, caminhamos no sentido de evidenciar a dimensão política do processo de metropolização, presente nas estratégias que determinam o momento histórico contemporâneo. Considerando o momento atual, observamos também, a emergência de outra problemática fundamental para o entendimento da sociedade pós-urbana: àquela relacionada ao risco, ao medo e à insegurança (Beck, 2011; Bauman, 2008; Foucault, 2008; Haesbaert, 2014-2015). É nesta perspectiva que, ao escrever "política", inserimos o prefixo "bio" entre parênteses, para focalizar os dispositivos, técnicas e estratégias de segurança que tem papel fundamental na 
formação das metrópoles e na sustentação de seus centros de poder - indispensáveis à governança e governamentalidade metropolitana. De acordo com Haesbaert (p.157, 2014) a insegurança passa a ser tomada como "um modo de gestão da vida coletiva", acionando o Estado e as classes hegemônicas pela via da gestão dos riscos e das ameaças; deste modo, as técnicas de segurança "têm na modificação do espaço e do território um de seus elementos constituintes fundamentais" (idem, p.163).

É Michel Foucault (2008), no curso Segurança, Território, População, ministrado no Collège de France em 1978, quem irá discutir os dispositivos de segurança que "trabalham, criam, organizam, planejam um meio antes mesmo da noção ter sido formada e isolada". Esta noção de "meio", proposta pelo autor, consiste num campo de intervenção que "procura atingir a população", considerada como uma multiplicidade de indivíduos que são e que só existem profunda, essencial e biologicamente ligados à materialidade dentro da qual existem (idem).

O meio vai ser, portanto, aquilo em que se faz a circulação. O meio é um conjunto de dados naturais, rios, pântanos, morros, é um conjunto de dados artificiais, aglomeração de indivíduos, aglomeração de casas, etc. (...) Portanto, é esse fenômeno de circulação das causas e dos efeitos que é visado através do meio. (Foucault, p.28, 2008). [grifo meu].

A noção de "meio" nos auxilia a tratar a problemática biopolítica (controle e segurança da população no território) da circulação (bens, pessoas, informação), questão crucial à compreensão da dinâmica das metrópoles. A partir de tal definição biopolítica proposta por Foucault, o que deseja-se apreender com a noção de "meio" são os fluxos, ou melhor, "o aumento - e, correlativamente, o controle - da circulação, da fluidez no/do espaço" (Haesbaert, p.171, 2014). Nesta noção está implicada a produção, organização e ordenamento do território, pois um espaço é concebido mentalmente/informacionalmente - neste caso, nos marcos do Estado - para comportar a fluidez e circulação da população. 


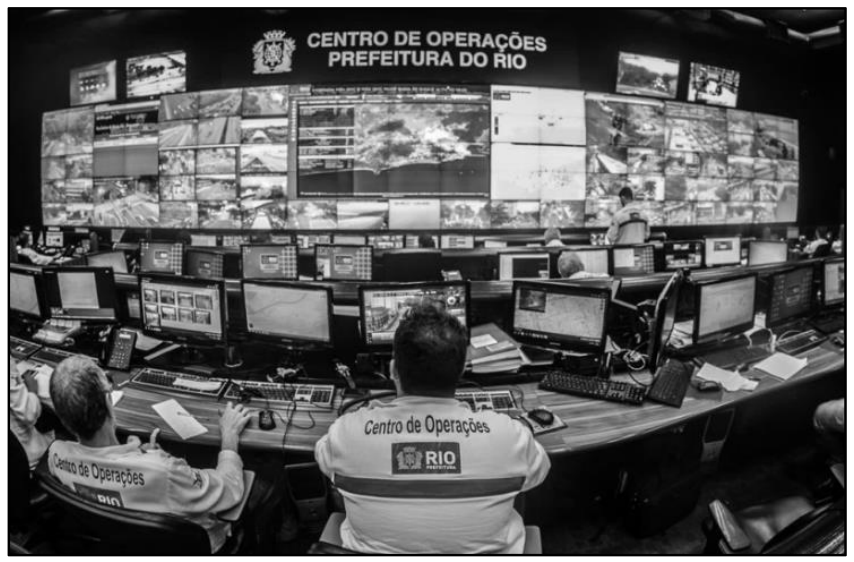

Figura 1. Sala principal do Centro de Operações Rio (COR). Fonte: Centro de Operações Rio.

É a partir dessa noção que capturamos uma relação entre segurança e metropolização, enfatizando sua dimensão (bio)política, uma vez que os serviços de ordem superior da esfera pública e privada se debruçam, cada vez mais, sobre questões relacionadas à vigilância, monitoramento e controle da circulação e dos fluxos no espaço da urbanização dispersa, da metropolização. Este é o caso do Centro de Operações Rio (COR), apresentado na Figura 1: Um painel composto de várias telas exibe, ao centro, um sistema de informações geográficas cercado de imagens de câmeras espalhadas por áreas da cidade, operados por uma equipe de funcionários. O sistema de informações geográficas pode ser apreendido a partir da noção de meio enquanto um espaço informacional concebido para a regulação da desordem, a gestão de riscos e controle da fluidez/circulação da população. 0 COR constitui-se enquanto equipamento fundamental de ordenamento territorial no âmbito de uma reconfiguração do papel do Estado, que, como veremos no próximo item, cada vez mais é convocado a interferir em situações de crises, riscos, ameaças e in-segurança prerrogativas que marcam sua des-re-territorialização.

\section{In-segurança e des-re-territorialização do Estado}

Buscando desconstruir algumas ideias acerca da relação entre Estado, poder e território, Haesbaert (2014) traz alguns esclarecimentos que são norteadores ao debate empreendido aqui. Embora o Estado tenha se projetado como um padrão universal e exclusivista de territorialidade, é preciso considerar "uma espécie de dialética territorializadora- 
desterritorializadora", pois os Estados são "entidades dinâmicas e historicamente construídas" (idem, p.129), sendo muito mais correto pensa-lo enquanto "processos de estatização". O autor discute que, se o território deve ser visto muito mais através das dinâmicas de des-re-territorialização, o Estado também o deve, pois configura um processo, cuja crise torna-se evidente - algumas de suas prerrogativas são colocadas em xeque diante de outras formas de des-territorialização. Contudo, como observamos na seção anterior, a função de regulação e controle espacial permanece enquanto incumbência do Estado, principalmente a partir da problemática ou questão da in-segurança (Haesbaert, p.143, 2014).

Capturando a expressão de governamentalidade a partir dos centros de poder, Richard Peet (2007) afirma que "o termo se refere à modelagem da conduta humana para fins definidos pelas autoridades e agências maiores do que o Estado, particularmente pelas instituições que invocam a verdade por meio do uso de recursos, expedientes e técnicas científicos" (Peet, p.29, 2007). Porém, discordamos quando o geógrafo coloca o Estado numa posição inferior em relação às autoridades e agências "maiores". Isto porque, de acordo com Haesbaert (2014), embora a lógica mercantil acabe por "comandar" a ação do Estado e, algumas das prerrogativas vinculadas a ele tenham sido colocadas em xeque, é preciso percebê-lo dentro de dinâmicas de des-re-territorialização, ou seja, de uma recomposição de seus papéis, no qual a problemática do controle da população (e de sua circulação) é uma questão fundamental na re-territorialização do Estado contemporâneo. Portanto, como afirma Haesbaert (2014), a governamentalidade não se reduz à ação do Estado e inclui as múltiplas "artes de governo" ou de "governamento" (idem, p.175). O Estado expressa um tipo de relação de poder entre outras relações, processos (e atores) de poder.

Podemos visualizar diversas intervenções no espaço que são expressão de tais relações de poder no sentido da governamentalidade, isto é, que manifestam processos de des-reterritorialização, desde o planejamento urbano promovido pelo Estado, até as intervenções conjuntamente a outros atores (Planejamento estratégico) promovendo uma territorialização hegemônica, que, de acordo com Ferreira (2014), introjeta no cotidiano dos moradores da cidade diversas tecnologias e mecanismos de controle do espaço que passam a ser naturalizados. 
Nas palavras de Foucault (2008), "a emergência de tecnologias de segurança (...) têm por função modificar o destino biológico da espécie" (idem, p.15). A estas tecnologias, estratégias e políticas de poder direcionadas àquilo que, "na espécie humana constitui suas características biológicas", é o que Foucault denomina "biopoder". De acordo com Haesbaert (2014), ao falar de "sociedades de segurança" ou "sociedade de controle" considera mais adequado falar da questão da segurança e do controle como uma das dimensões privilegiadas na sociedade atual.

\begin{abstract}
Segurança e biopoder, portanto, encontram-se imbricados de modo indissociável. Podemos dizer que a "população", inclusive em sua condição mais estritamente biológica, torna-se uma questão de "segurança": sua reprodução, sua fertilidade, sua mortalidade - que envolvem (...) sua circulação. As questões biopolíticas de população são agora, igualmente, questões de segurança, pois envolvem fenômenos coletivos, "de massa", fenômenos seriais, "aleatórios e imprevisíveis". (Haesbaert, p.172, 2014).
\end{abstract}

As intervenções e modificações no espaço a partir do Estado configuram seu processo de des-re-territorialização no curso da metropolização, revelando essa dimensão privilegiada a biopolítica - e, para além disso, representações e concepções de espaço e território inscritas no interior de suas medidas e práticas de governamentalidade. O "meio", numa dimensão mais concreta/funcional, é a própria configuração espacial que cria as condições de reprodução da metrópole e atinge a população, modelando sua conduta. Portanto, torna-se imprescindível reconhecer como o Estado "pratica" o espaço e o território, pois trata-se de um ator privilegiado no que tange ao ordenamento espacial e programação deste "meio".

Para o geógrafo David Harvey (2006), “o problema da concepção correta do espaço é resolvido pela prática humana em relação a ele", isto é, "as diferentes práticas humanas criam e usam diferentes concepções do espaço" - as respostam se situam na prática humana. Considerando a problemática em questão, a reconfiguração dos papéis desempenhados pelo Estado é determinada pelas demandas para as quais ele é convocado a agir e, é a partir das respostas (re-ações) às demandas que podemos capturar as concepções espaciais vinculadas e veiculadas.

Com a ascensão do neoliberalismo enquanto projeto teórico de reorganização do capitalismo internacional e projeto político de restabelecimento das condições de acumulação do capital e de restauração do poder das elites econômicas (Harvey, 2008), as finalidades do Estado são modificadas, na teoria e na prática. Segundo Harvey (idem), na 
teoria, o Estado neoliberal deve buscar reorganizações internas e novos arranjos institucionais que melhorem sua posição competitiva como entidade diante dos outros. A governança deve ser entregue aos especialistas e às elites, com forte preferência ao governo por ordem executiva e decisão judicial, em lugar da tomada de decisões democrática e parlamentar, já que para os neoliberais, uma governança pelo regime da maioria é considerada uma ameaça potencial aos direitos individuais e às liberdades constitucionais. Na prática, ao Estado cabe criar um clima favorável aos negócios ou investimentos para empreendimentos capitalistas, favorecendo a integridade do sistema financeiro em detrimento do bem-estar da população ou do meio ambiente. É nesta via que observamos um crescente aumento das parcerias público-privadas (PPP), um conjunto complexo de forças mobilizado por diversos atores sociais, onde está o poder real da organização urbana, denominado "governança urbana" por Harvey (2005): constituída por empreiteiras e construtoras, agentes e incorporações imobiliários, bancos, indústria cultural (mídia), instituições e organizações não governamentais (ONG), e, finalmente, o governo e a administração urbana, que desempenham apenas o papel de facilitador e coordenador.

\footnotetext{
Os negócios e corporações não só colaboram intimamente com atores do governo como chegam mesmo assumir um forte papel na redação de leis, na determinação das políticas públicas e na implantação de estruturas regulatórias. (...) Surgem padrões de negociação que incorporam os negócios e por vezes interesses profissionais na governança mediante contatos próximos e por vezes secretos. (Harvey, p.87, 2008).
}

Esses procedimentos neoliberais caracterizam o que Vainer (2011) denominou "cidade de exceção", uma referência ao "estado de exceção" de Agamben (2004), que seria uma nova forma de regime urbano, no qual os aparatos institucionais formais progressivamente abdicam de parcela de suas atribuiç̧̃es e poderes. Para o autor, a cidade de exceção é o lugar da "democracia" direta do capital, na qual o poder é transformado em instrumento para colocar a cidade a serviço do interesse privado de diferentes grupos, de maneira direta e sem mediações na esfera da política (consultas públicas, processos participativos, tomada de decisão coletiva). Para Vainer (2011) essa governança produz e reproduz situações e práticas de exceção, em que poderes são transferidos a grupos de interesse empresarial. 0 estado de exceção define seu patamar ou se conceito limite, enquanto suspensão da própria ordem jurídica (Agamben, p.15, 2004). O filósofo italiano apresenta o estado de exceção como a forma legal daquilo que não pode ter forma legal, isto é, um limiar onde fato e direito parecem tornar-se indiscerníveis, criando "terras de ninguém", onde a 
aplicação da lei é suspensa, mas, enquanto tal permanece em vigor (Agamben, 2004). Neste sentido, percebemos uma nebulosidade entre o estabelecimento da norma e sua aplicação, que caracteriza a zona de indiferenciação de um estado de exceção - o que está dentro e fora do ordenamento jurídico se torna indeterminado, proporcionando as condições para que "procedimentos de fato, em si extra ou antijurídicos, transformem-se em direitos e, onde as normas jurídicas se indeterminem em mero fato" (Agamben, p.45, 2004).

De acordo com Harvey (2008), o Estado neoliberal recorre a legislações coercivas e táticas de policiamento para dispersar ou reprimir formas coletivas de oposição ao poder corporativo, lançando mão de dispositivos de monitoramento e vigilância, amparado pelo discurso do risco e da insegurança que, segundo Haesbaert (2013), legitima a necessidade de uma "sociedade do controle". Esta é uma das demandas para a qual o Estado também é convocado a intervir, motivado, sobretudo, pela emergência da "população", o ser humano concebido enquanto espécie, uma entidade biológica que se reproduz, se expande e circula; e sobre o qual deve-se prolongar a vida ("fazer viver") ou expor à morte, uma desqualificação progressiva desta no intuito de evitar e/ou conter a proliferação dos riscos e ameaças à vida. Como demonstra Haesbaert (2013), o biopoder enquanto modalidade de poder é profundamente incorporado pelo Estado, reestruturando o seu papel, que se mobiliza em direção aos problemas do "meio" - fluxos e circulação da população.

Segundo Agamben (p.146, 2002), a segurança se tornou o princípio básico da atividade do Estado, e tais medidas exigem constante referência a um estado de exceção:

enquanto o poder disciplinar isola e fecha territórios, as medidas de segurança conduzem a uma abertura e à globalização; enquanto a lei deseja prevenir e regular, a segurança intervém nos processos a fim de dirigi-los. Em suma, a disciplina quer produzir a ordem, a segurança quer regular a desordem. (Agamben, p.145, 2005).

Aos mecanismos de segurança caberá prever as ameaças e minimizar o que é inconveniente e fator de risco/ameaça, produzindo um espaço construído a partir dessas premissas, isto é, da exceção tomada como regra para ações e planejamento - fundamento do processo de militarização do espaço ou, de um "urbanismo militarizado" (Graham, 2016). De acordo com o geógrafo britânico,

A militarização também envolve a normalização dos paradigmas militares de pensamento, ação e política; esforços de disciplinar agressivamente corpos, espaços e identidades consideradas não condizentes com noções masculinizadas (e interconectadas) de nação, cidadania ou corpo; e o uso de uma ampla e diversificada propaganda política que romantiza ou higieniza a violência como um 
meio de vingança legítima ou de conquista de algum propósito divino. Acima de tudo, a militarização e a guerra organizam a "destruição criativa" de geografias herdadas, economias políticas, tecnologias e culturas (Graham, p.122, 2016).

Sendo assim, constatamos que, num contexto de neoliberalização e segurança/militarização, há pelo menos duas demandas pelas quais o Estado é convocado a atuar, ou seja, que engendram práticas estatais e, portanto, evidenciam concepções espaciais. Se o espaço é um produto social (Lefebvre, 1991) e, enquanto tal, também é produtor das condições sociais, como podemos focalizar a problemática em questão a partir de conceitos geográficos?

De acordo Haesbaert (2014) o conceito ilumina tanto a realidade empírica quanto o pensamento ou racionalidade, sendo a problemática seu ponto de partida fundamental. Os conceitos também problematizam a realidade/racionalidade. Segundo o autor, algumas problemáticas definem o foco central do conceito, evidenciando determinadas questões ou relações e deixando outras em segundo plano, ou fora de foco. Contribuindo neste sentido, ao apresentar a abordagem Deleuziana acerca da teoria e conceitos enquanto "caixa de ferramentas", Cruz (2013) desdobra as "linhas do novelo" que constituem os conceitos, atentando para as linhas de visibilidade/enunciação, para as linhas de força e, por último, às linhas de objetivação. Em suma, ao incidir (como um raio de luz) sobre a realidade, cada conceito ilumina essa superfície, criando "visibilidades e dizibilidades", ao mesmo tempo em que, produz sombras ou penumbras - o que está fora da incidência ou foco central. Este movimento também institui e produz a realidade, característica das "linhas de força", cuja capacidade criativa e, portanto, política, revela a intervenção que os conceitos provocam a partir dessa incidência. Portanto, além de instaurar uma forma de compreensão, de ver e dizer o real, os conceitos também intervêm nesta realidade, caracterizando as "linhas de objetivação". Se às práticas do Estado estão vinculadas e são veiculadas concepções/conceituações acerca do espaço, é preciso lançar mão de uma abordagem capaz de apreender qual é a natureza dessa espacialidade.

Diante de tais considerações, a contribuição conceitual elaborada pelo geógrafo inglês Stuart Elden (2016) é bastante profícua para o debate e a problemática em voga. Recuperando a abordagem de Edward Soja, quando sugere uma análise tripartite de recurso, poder e organização espacial, Elden (2016) nos conduz a pensar em três conceitos inerentemente relacionados - terra, terreno e território - contudo, necessariamente 
distintos. Terra é uma relação de propriedade, uma questão político-econômica; Terreno é uma relação de poder, o controle que permite o estabelecimento e manutenção da ordem (político-estratégica, na acepção militar); Território é algo que faz parte de ambos, entretanto, é mais que do que os dois (idem, p.47). Embora cada um deles seja atingido por relações de poder, Território pode ser entendido como uma tecnologia política, compreendendo as técnicas de medição de terra e controle do terreno (idem, p.54): o conceito deve ser pensando em conjunto com o econômico e o estratégico, terra e terreno. As modalidades de representação cartográfica, os dispositivos jurídicos e da lei, o cálculo e a quantificação revelam uma relação entre estratégias e técnica que,

nos permitem compreender o território como um modo distinto de organização social/espacial, que é historicamente e geograficamente delimitado e dependente, em vez de apenas pulsão biológica ou necessidade social. (Elden, p.52, 2016).

De acordo com Elden $(p .53,2016)$ território é melhor compreendido através de uma análise da relação do Estado com a emergência da categoria "espaço".

\begin{abstract}
Território é uma questão histórica: é produzido, mutável e fluído. É geográfico não simplesmente porque é uma das maneiras de ordenar o mundo, mas também porque é profundamente desigual em seu desenvolvimento. É uma palavra, um conceito e uma prática em que a relação entre estes só pode ser apreendida genealogicamente. É uma questão política, mas em um sentido amplo: é econômico, estratégico, jurídico e técnico. Território deve ser abordado politicamente em sua especificidade histórica, geográfica e conceitual (Elden, p.54, 2016).
\end{abstract}

Esta conceituação permite focalizar o modo pelo qual o Estado "pratica" ou "usa" o espaço, isto é, as relações de poder contidas nas manifestações de sua espacialidade, considerando o processo de metropolização que está em curso num contexto de neoliberalização e em sua dimensão biopolítica. Enquanto terra o espaço é concebido como mercadoria ou negócio, ele é fragmentado, parcelado e colocado à venda - para isso cooperam o Planejamento estratégico, o city-marketing e os projetos de renovação/revitalização urbana, como é o caso do Porto-Maravilha na cidade do Rio de Janeiro. O Estado, em conjunto com a iniciativa privada, se encarrega de coordenar e facilitar o andamento de projetos e empreendimentos cuja finalidade é atrair os megainvestidores globais. Enquanto terreno o espaço é alvo de estratégias militares, tendo como maior evidência na contemporaneidade as cercas e os novos muros (Haesbaert, 2014), segurança privada, câmeras de monitoramento e tecnologias de vigilância. São marcas desta concepção de território: as Unidades de Polícia Pacificadora (UPP), o Centro de Operação Rio (COR), os Centros Integrados de Comando e Controle (CICC) e a Cidade da Polícia, representando as 
tecnologias, estratégias e políticas de segurança que constituem a faceta biopolítica do processo de metropolização do espaço na cidade do Rio de Janeiro, como apresentado na figura 2. As UPPs fazem parte de um programa de segurança pública, empreendido no fim de 2008, pela Secretaria de Estado de Segurança do Rio de Janeiro, a partir dos princípios de "Polícia de Proximidade", que instalou 37 unidades no município do Rio de Janeiro e uma unidade na comunidade da Mangueirinha, no município de Duque de Caxias. É possível perceber a concentração das UPPs na região central do núcleo metropolitano, onde estão localizadas favelas marcadas pela presença do narcotráfico e da criminalidade violenta. Além das UPPs, ressaltamos a presença do COR e do CICC, "um grande big brother de vigilância metropolitana (...) que tem a função de monitorar o espaço do município em 'tempo real' (...) operando sobre uma enorme base de dados de natureza geográfica" (Haesbaert, 2015).

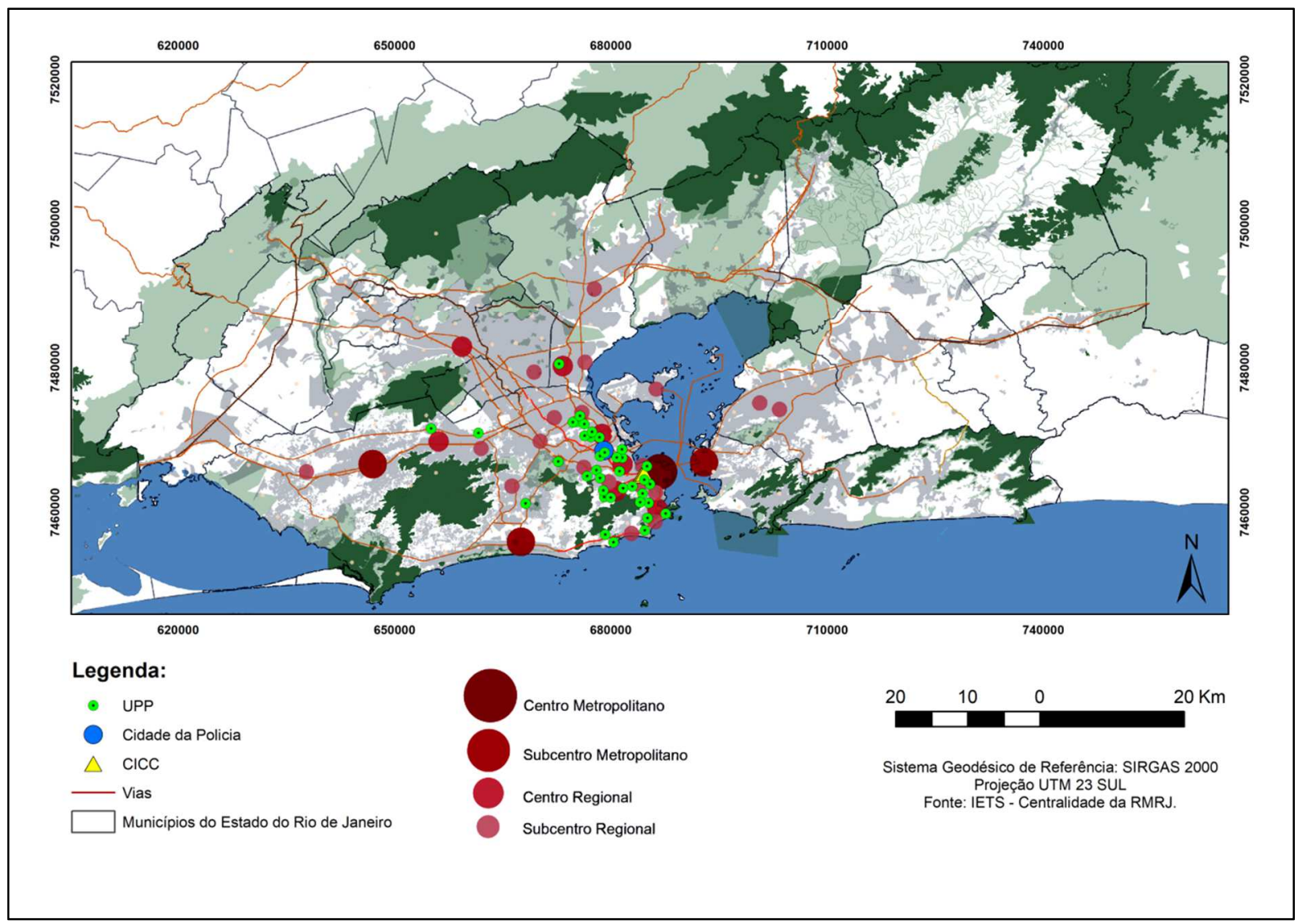

Figura 2. A espacialidade da centralidade e os dispositivos de controle 
A Região Metropolitana do Rio de Janeiro (RMRJ) é composta de 21 municípios $^{2}$, sendo a cidade do Rio de Janeiro o núcleo da metrópole. A partir de um estudo acerca das centralidades urbanas da RMRJ, realizado pelo Instituto Econômico Trabalho Social (IETS), no ano de 2016, observou-se a forte centralidade exercida pelo município do Rio de Janeiro, seguida dos subcentros representados pelo bairro de Campo Grande, Barra da Tijuca e o município de Niteroi. Enquanto centro de alcance regional, figuram alguns bairros do município carioca, como Tijuca, Bonsucesso/Ramos/Olaria, Bangu, Botafogo, São Cristóvão e os centros do município de Duque de Caxias e Nova Iguaçu. O IETS baseou o conceito de centralidade, utilizado em seu estudo, a partir da relação entre a concentração espacial de atividades nos centros e sub-centros metropolitanos, bem como a diversidade de funções que os articulam às demais localidades do tecido metropolitano. Os indicadores utilizados para apreender a centralidade foram a presença de órgãos do Estado, sedes e filiais e de empresas, tal como,

(...) a oferta de distintos equipamentos e serviços - informações de ligações de transporte, de deslocamentos para internações hospitalares, das áreas de cobertura das emissoras de televisão, da oferta de ensino superior, da diversidade de atividades comerciais e de serviços, da oferta de serviços bancários, e da presença de domínios de Internet, as principais ligações de transportes regulares, os principais destinos dos moradores dos municípios pesquisados para obter produtos e serviços (tais como compras em geral, educação superior, aeroportos, serviços de saúde, bem como os fluxos para aquisição de insumos e o destino dos produtos agropecuários). (Relatório Final, IETS, p.48, 2016).

Neste sentido, compreende-se que a forte centralidade exercida pelo núcleo da metrópole deve-se à concetração espacial de atividades e serviços de ordem superior, da esfera pública ou privada, relacionados ao comércio, mobilidade, finanças e informação. Como dito anteriormente, as tecnologias e políticas de segurança incidem e também se concentram sobre esta região, apontando para uma territorialização do Estado que concebe o espaço como "meio": objeto de ordenamento e instrumento de dominação (funcional e simbólica) da circulação da população enquanto espécie biológica. São processos indutores e induzidos de e por territorializações voltadas ao fortalecimento do poder político-econômico públicoprivado, da disciplinarização dos espaços e monitoramento dos fluxos e circulação. Nesse

\footnotetext{
${ }^{2}$ Conforme o Projeto de Lei Complementar n10/2015, a Região Metropolitana do Rio de Janeiro é composta pelos seguintes municípios: Rio de Janeiro, Belford Roxo, Duque de Caxias, Guapimirim, Itaboraí, Japeri, Magé, Maricá, Mesquita, Nilópolis, Niterói, Nova Iguaçu, Paracambi, Queimados, São Gonçalo, São João de Meriti, Seropédica, Tanguá, Itaguaí, Rio Bonito e Cachoeiras de Macacu.
} 
aspecto, há uma íntima relação entre metropolização e biopolítica, ou melhor, $o$ desvelamento do caráter biopolítico do processo de metropolização do espaço.

No âmbito de tais processos em curso, no que concerne às políticas e medidas de segurança na cidade do Rio de Janeiro, a gestão estatal da esfera pública (poder municipal e estadual) produziu uma série de formas-conteúdos reveladoras da generalização do controle com vistas à regulação da desordem, aproximando-se do que Haesbaert (2014) denominou "contenção-territorial", para abordar a ambiguidade envolvida nas modalidades contemporâneas de territorialização, que lidam com a impossibilidade de fechamento integral.

A cidade do Rio de Janeiro, em particular, tornou-se um dos espaços emblemáticos onde a in-segurança é central na construção de todo um projeto políticoeconômico pautado no discurso do controle social que implica o próprio controle e/ou a reconfiguração, num complexo processo de des-reterritorialização. (Haesbaert, p.226, 2015)

Diante da impossibilidade de clausura ou confinamento da população, cuja proliferação e circulação são uma ameaça à ordem, a solução do "Estado de segurança" reside em "promover medidas paliativas de contenção, técnicas/procedimentos de evitação ou de repressão, tentando simplesmente dirimir os efeitos dessa dinâmica social precarizadora e excludente" e "conter os espaços dos grupos subalternos" (Haesbaert, 2014; 2015). Como manifestação das medidas e procedimentos que caracterizam a contenção territorial figuram as Unidades de Polícia Pacificadora (UPP), a Cidade da Polícia, o Centro de Operações Rio (COR) e o Centro Integrado de Controle e Comando (CICC). Proteção e vigilância para quem?

\section{Considerações finais ou "a espacialidade da biopolítica no ordenamento do território"}

A enorme densidade de fluxos e as redes materiais e imateriais são componentes essenciais na dinâmica da metropolização. O território que se implica pelo processo de metropolização caracteriza-se pelos múltiplos, intensos e permanentes fluxos de pessoas, mercadorias e informações (Lencioni, p.48, 2006). Os fluxos evidenciam as transformações que marcam a 
história urbana atual, onde os fenômenos de dilatação e a dispersão predominam sobre as demais formas do urbano (Lencioni, p.7, 2015b).

É neste sentido que Lencioni $(2015,2015 b)$ utiliza a metáfora de uma "nebulosa urbana" fazendo referência ao geógrafo Jean Gottmann - considerando seu "corpo difuso", isto é, "uma urbanização difusa sob o império dos fluxos em que o binômio formado pelos eixos de circulação e os automóveis são, dentre outros elementos principais, estruturantes". Contudo, ao abordamos as regiões metropolitanas, enfatizamos o conceito de região, pois, de acordo com a autora, é indispensável haver uma unidade interna, uma coesão, a constituição de uma totalidade para que a região se constitua enquanto tal. Neste sentido, os fluxos são elementos constitutivos da integração. Ao tratar sobre a abordagem de megalópoles por Gottmann, Lencioni afirma que:

Os fluxos, os movimentos, as ligações (linkages) entre as partes, bem como as complementaridades entre partes e funções, que se dão pela mediação de diversas dinâmicas e processos e que se desenvolvem no interior da região, são constitutivos da integração. Por isso, a megalópole como região, como região urbana e não como área urbana deve apresentar coesão interna, deve apresentar integração socioespacial. Isso significa dizer que não é qualquer área urbana onde predomina a dispersão que se constitui numa metrópole. (Lencioni, p.49, 2015).

Apresentando uma discussão acerca de totalidade e fragmentação, a autora demonstra que a integração é o elemento-chave que assegura a coesão na dispersão, isto é, que garante o conjunto. Para Lencioni (2015b) é o exame da integração na dispersão que permite compreender os limites da urbanização dispersa, pois é a integração que permite entender a tensão que existe entre fragmentação e totalidade. Portanto, ao utilizar a palavra região, a autora pretende expressar o sentido de integração,

indispensável para se compreender uma urbanização difusa e o desenvolvimento de regiões urbanas extensas territorialmente e em coalescência, a expressar unidade na fragmentação. (Lencioni, p.10, 2015b).

Em obras de referência para a presente pesquisa, Sandra Lencioni discute a integração/coesão a partir do conceito das redes, que se constituem como forças produtivas fundamentais de uma economia globalizada e evidenciam a dimensão do espaço enquanto meio, isto é, como mediação necessária à reprodução do capital em escala globalizada. Além disso, ao classifica-las em dois tipos - redes de proximidade absoluta e rede de proximidade relativa - afirma seu papel enquanto um dos elementos estruturadores de novos arranjos territoriais, como o da cidade-região (Lencioni, p.71, 2006b); por meio delas se garante a continuidade na descontinuidade, a unidade na fragmentação, como também, 
a distinção e separação do que tem capacidade de se conectar daquele que não o tem (Lencioni, 2010). Podemos observar a evidência dessas redes, no âmbito da in-segurança, tomando como evidência empírica os Centros Integrados de Comando e Controle. De acordo com Haesbaert (2015), no bojo das transformações urbanas e como um requisito internacional para a recepção da Copa do Mundo de 2014 e dos Jogos Olímpicos de 2016, o Rio de Janeiro e várias cidades brasileiras passaram a sediar - a partir de 2011 - um dos mais sofisticados centros de televigilância do mundo, representando,

a instituição de um megadispostivo urbano, que, a partir de agora, tende a ser um componente indispensável no ordenamento dos espaços decisórios, centrais, das grandes metrópoles - dentro da lógica (...) das sociedade denominadas por alguns "de controle" ou "de segurança" (Haesbaert, p.229, 2015).

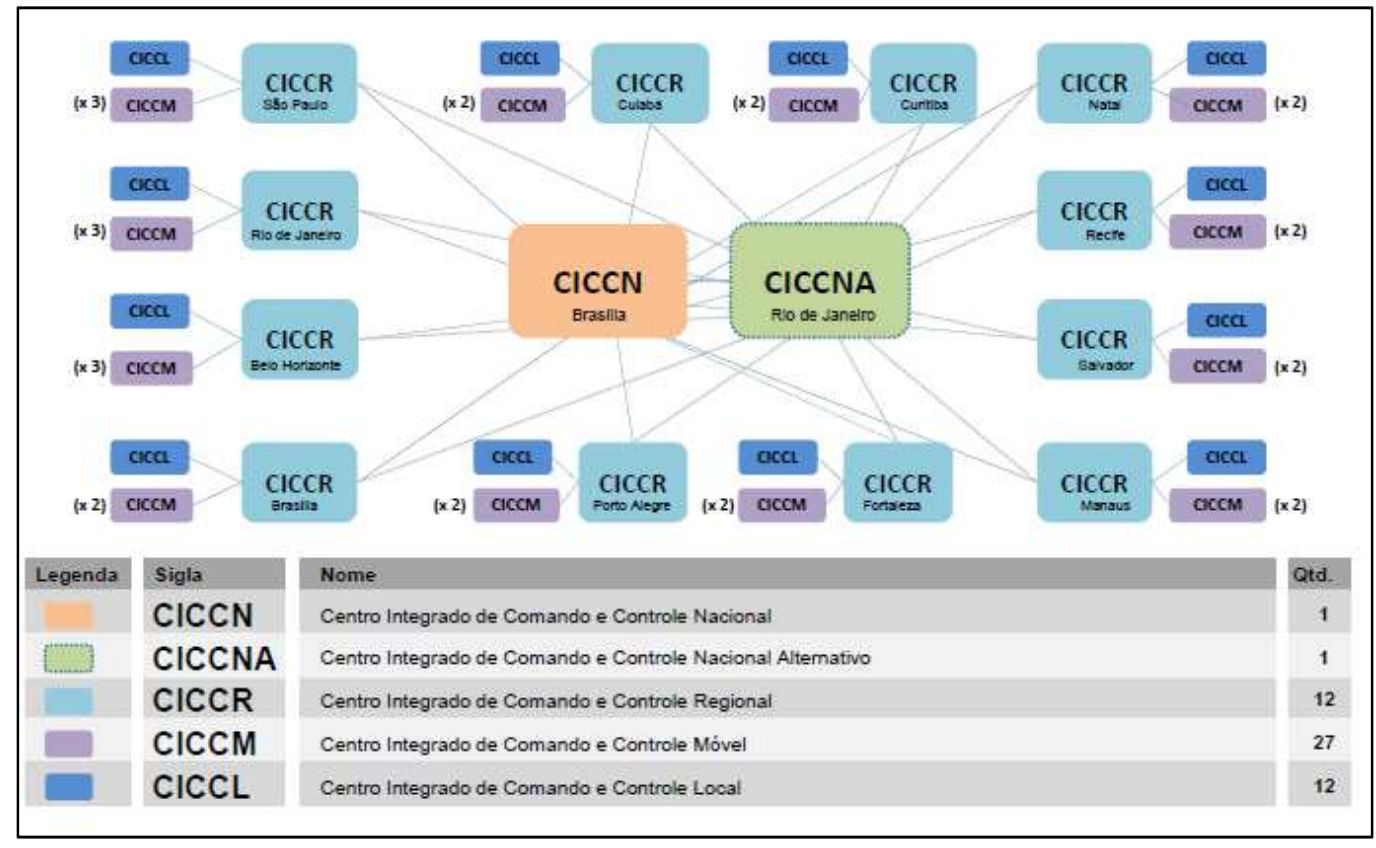

Figura 3. Esquema de integração em rede dos Centros Integrados de Comando e Controle. Fonte: Secretaria Extraordinária de Segurança para Grandes Eventos - SESGE.

Os Centros Integrados de Comando e Controle estão subdividos em categorias - nacional, regional, móvel e local. Os CICCs nacionais localizam-se em Brasília e no município do Rio de Janeiro. Os centros de categoria regional estão localizados em três cidades do sudeste (São Paulo, Belo Horizonte e Rio de Janeiro), duas cidades da região sul (Curitiba e Porto Alegre), quatro cidades da região nordeste (Natal, Recife, Salvador e Fortaleza) um no município de Manaus (região norte) e outro em Cuiabá (região centro oeste). Todos os centros estão interligados e conformam uma rede de produção e transmissão de informações. No caso do CICC localizado no Rio de Janeiro, tem-se o decreto 44.698, de fevereiro de 2014, que instituti o megadispostivo, no tocante à necessidade integrar os serviços de atendimentos 
nas áreas de segurança pública, defesa social e civil, gestão de crises e ocorrências em grandes eventos, desatres, eventos de defesa social de alto risco e "eventos que fujam à normalidade, a critério do Chefe de Poder Executivo ou a qualquer outra autoridade por ele delegada". O CICC do Rio de Janeiro consiste como um backup do CICC Nacional (Brasília) e está conectado através de cabos de fibra ótica, funcionando por meio de uma Virtual Private Network (VPN), uma rede privada de internet exclusica para o $\mathrm{CICC}$ e seus equipamentos. Segundo Haesbaert (2015), o projeto tem como empresas parceiras a Cisco, Cyrela, Facilities, Muell, Oi, Samsung e IBM.

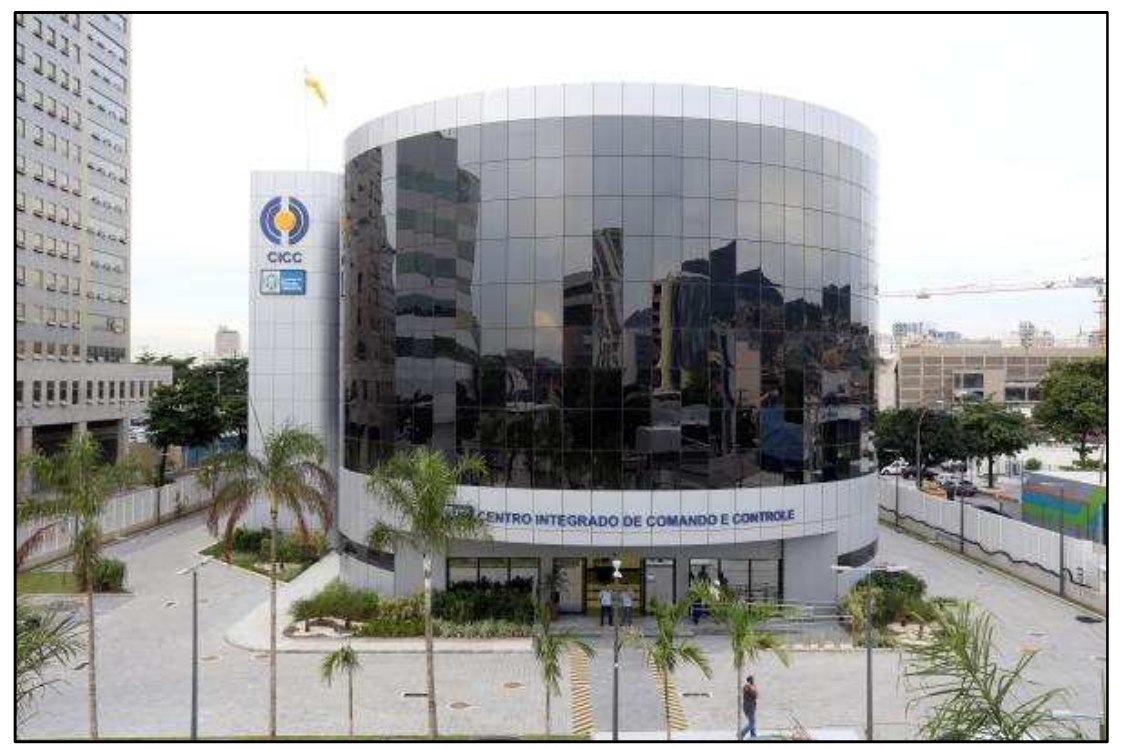

Figura 4. Centro Integrado de Comando e Controle do Rio de Janeiro. A estética do edifício corresponde ao padrão arquitetônico globalizado de uma cidade pós-moderna. Foto: Governo do Estado do Rio de Janeiro.

Uma vez que se pretende garantir a unidade das partes de uma totalidade, a partir de redes de integração - como elemento que assegura a coesão na dispersão - estamos lidando com um espaço de natureza fragmentada. É neste sentido que a Lencioni (2010; 2015) oferece um recurso-chave à análise do espaço ao resgatar a tríade que considera o espaço da sociedade capitalista como homogêneo, fragmentado e hierarquizado. A homogeneidade do espaço corresponde às semelhanças paisagísticas e similaridades (Lencioni, 2015). Aderese aos modelos de sucesso internacional que tornam as cidades meras-cópias de edifícios e arquitetura; a homogeneização se revela como tendência nas formas e nas funções. Contudo, tal homogeneidade se fragmenta, mesmo que somente na aparência; Tanto nas formas quanto nas funções, é possível perceber o processo de fragmentação, assentada numa concepção de espaço e cidade como mercadorias para atender o mercado imobiliário. 
Em Lencioni (2010), observamos uma relação entre homogeneidade e as formas do espaço: as cidades, edifícios, centros comerciais, avenidas, segundo a autora, "atestam as equivalências, o mesmo". Em trabalho mais recente, Lencioni (2015) aponta também para as similaridades relativas ao processo de produção, isto é, na padronização dos procedimentos de produção do espaço construído, o que nos lembra do debate de Milton Santos (2006) acerca da unicidade da técnica. Fazendo referências às mesmas obras mencionadas, percebemos uma relação entre a fragmentação e as funções do espaço, uma vez que as formas desempenham funções que lhes são designadas - como moradia, lazer, negócios, controle: a fragmentação do espaço remete à divisão das formas-conteúdo segundo as diversas funções e usos que ele abriga. Por último, é possível perceber uma relação entre hierarquia e estrutura. De acordo com Lencioni (2010), "a hierarquização permite o domínio do poder e do comando, que são instrumentais para garantir a totalidade do conjunto". Para Milton Santos (2008), "estrutura implica a inter-relação de todas as partes de um todo; o modo de organização ou construção". Nesta perspectiva, há uma nítida referência à organização - o modo de estruturação - dessa totalidade. Assim, a hierarquização, ao manifestar a dominação que assegura a unidade do conjunto, é um processo de ordenamento das partes cujas funções foram segmentadas no curso dos processos de homogeneização e fragmentação. Conforme Lencioni (2015), embora seja recorrente o uso da tríade analítica, muitas vezes ela termina por ser reduzida aos termos homogeneização-fragmentação, olvidando o termo hierarquização. Podemos perceber uma relação entre a tríade homogêneo-fragmentado-hierarquizado e outra tríade analítica, a saber, forma-função-estrutura. Neste sentido, advogamos que a espacialidade biopolítica no ordenamento do território desdobra-se a partir do processo de hierarquização (âmbito do domínio e do poder) que estrutura e ordena as formas-conteúdo conforme suas funções, dentre as quais, estão aquelas ligadas ao controle e à segurança, correspondendo ao que denominamos "espaços de comando": os "centros de poder" dos quais partem as normas, direções e decisões que, na esfera de uma "sociedade do controle ou de segurança", atuam na programação, monitoramento e vigilância da vida cotidiana na metrópole.

Observamos que, a partir da emergência das tecnologias de informação e comunicação, a hierarquização do espaço vem se desempenhando, predominantemente, não mais na modalidade piramidal, mas, de maneira reticular, isto é, a partir das redes que estruturam o 
território e garantem sua coesão. Portanto, as redes constituem não somente uma condição, mas, sobretudo, um meio pelo qual as técnicas e tecnologias voltadas ao controle e segurança da população se exercem no curso do processo de metropolização do espaço.

Ao nos debruçarmos sobre um processo que estrutura e integra (coesão) o espaço da metrópole, dando ênfase à hierarquização para focalizar essa dinâmica, não podemos olvidar que tal processo compõe uma tríade, a saber, homogeneização-fragmentaçãohierarquização. Deste modo, faz sentido pensar que o processo de hierarquização ordena os fragmentos de um espaço que, embora esteja submetido a uma tendência homogeneizadora, é continuamente diferenciado segundo as dinâmicas de des-valorização do solo urbano, concebido como uma mercadoria. Cabe lembrar que, o ato de ordenar é um ato de poder. Esse espaço corresponde ao espaço da sociedade capitalista, homogêneo, fragmentado e hierarquizado. Sendo assim, o processo de hierarquização estrutura as "formatações" que emergem do processo de homogeneização e as "funcionalidades" do processo de fragmentação - ou seja - é possível perceber um outro processo, o processo de estruturação, que consiste em ratificar formatações e funcionalidades, isto é, validar ou normatizar/normalizar formas-conteúdos e funções, exprimindo o poder na espacialidade e a espacialidade do poder.

Neste sentido, o processo de hierarquização é formalizador, uma vez que, ao ratificar as "formatações" que advém do processo de homogeneização, manifesta seu poder de "formalizar". Considerando a dimensão da fragmentação, a hierarquização é funcionalizadora: o processo de hierarquização ratifica as "funcionalidades", manifestando seu poder de funcionalizar. Portanto, no interior do processo de hierarquização - conjugado em sua tríade - e em diálogo com forma-função-estrutura, podemos apreender outra tríade: estruturação-formalização-funcionalização, que correspondem à dimensão biopolítica e, destarte, às relações de poder no/do espaço. Afirmamos que é a partir da estruturação-formalização-funcionalização do/no espaço da vida cotidiana que se garante a unidade do conjunto, a coesão e, também, a coerção na metrópole. Advogamos que a garantia da "normalidade" e da ordem no território ocorre por meio de procedimentos espaciais cujas normas estão inscritas nas formas geográficas, predefinindo ritmos, usos e práticas - pré-estabelecidas pelo Estado, seja a partir de ordenamentos jurídicos, seja a partir do uso da força e de seu braço repressor, neste caso, a polícia e suas tecnologias. 
Cientes de que a problemática não se esgota nessas linhas, julgamos ser válido repetir: a hierarquização é um processo de ordenamento das formas cujas funções foram segmentadas no curso dos processos de homogeneização e fragmentação. A hierarquização é um processo indispensável à fragmentação, uma vez que, enquanto ordena, ratifica funcionalidades, pré-estabelecendo ou prescrevendo usos sociais do/no espaço tempo. Da mesma maneira, é fundamental no âmbito da homogeneização, uma vez que opera por meio de um padrão/modelo pré-concebido de "formatações". É possível perceber essa dinâmica a partir dos Centros Integrados de Comando e Controle quando nota-se que um dado sistema técnico, ou, na visão de Foucault, determinada tecnologia de segurança, difunde-se por todo território, ultrapassando os limites das regiões metropolitanas ao criar redes de proximidade relativa (banda larga, fibra ótica). Deste modo, além de revelar o processo de des-re-territorialização do Estado no âmbito da in-segurança, também manifesta a dimensão biopolítica do processo de metropolização. Uma mesma formaconteúdo (CICCs - homogeneização), da qual se espera uma determinada função (fragmentação - comando e controle), estrutura territórios e cria uma coesão a partir das redes informacionais que expressam uma nova dimensão das hierarquias urbanas, não mais piramidais e topográficas, mas, reticulares e topológicas - apoiadas em dispositivos técnicoinformacionais voltados à gestão dos riscos e ameaças, à programação da vida cotidiana e da regulação da população e do território.

\section{Referências bibliográficas}

AGAMBEN, Giorgio. Estado de exceção. São Paulo. Boitempo, 2004. ISBN 9788575590577.

AGAMBEN, Giorgio. Sobre a segurança e o terror In: COCCO, Giuseppe; e HOPSTEIN, Graciela. (Org). As multidões e o Império: entre globalização da guerra e universalização dos direitos. Rio de Janeiro, DP\&A, 2002. $152 \mathrm{p}$.

CARLOS, Ana Fani Alessandri (Org.). Crise urbana. São Paulo, Contexto. 2015. ISBN 9788572448802.

CRUZ, Walter Carmo. A "Teoria como caixa de ferramentas": Reflexões sobre o uso dos conceitos na pesquisa em Geografia. In: Anais do X ENCONTRO ANPEGE, 2013, Campinas-SP, p.4454-4466.

ELDEN, Stuart. Terra, Terreno, Território. Revista GEOGRAFARES, no21, Janeiro-Junho, 2016. p.42-60.

FERREIRA, Alvaro. Metropolização do espaço, tensões e resistências: Entre espaços de controle e controle do espaço. In: Anais do XIII Colóquio Internacional de Geocrítica. Barcelona, 2014, 2014.p.1-18.

FOUCAULT, Michel. Segurança, Território, População. São Paulo, Martins Fontes, 2008. ISBN 9788533623774. 
FOUCAULT, Michel. Vigiar e Punir: nascimento da prisão. Petrópolis. Vozes, 29a edição, 2004, ISBN 8532605087.

GRAHAM, Stephen. Cidades sitiadas: o novo urbanismo militar. 1a ed, Boitempo, São Paulo, 2016, ISBN 9788575594995.

HAESBAERT, Rogério. Viver no limite: território e multi/transterritorialidade em tempos de in-segurança e contenção. 1 ed. Rio de Janeiro, Bertrand Brasil, 2014, ISBN 9788528615777.

HAESBAERT, Rogério. Do telecontrole à "ocupação": in-segurança e contenção territorial na metrópole carioca. In: Ferreira, Alvaro; Rua, João; Mattos, Regina Célia de (Org). Desafios da metropolização. Rio de Janeiro. Consequência, 2015.p.225-251.

HAESBAERT, Rogério. Globalização e fragmentação no mundo contemporâneo. 2ed. Revista e atualizada Niterói, EdUFF, 2013, ISBN 9788522808878.

HARVEY, David. Spaces of global capitalism. Towards a theory of uneven geographical development. New York: Verso, 2006, ISBN 1844675505.

HARVEY, David. O Neoliberalismo - História e implicações. São Paulo. Edições Loyola, 2008, ISBN 978851503566.

HARVEY, David. A Produção Capitalista do Espaço. São Paulo, Editora Annablume, 2005, ISBN 9788574194967.

LEFEBVRE, Henri. The Production of Space. Blackwell Publishing, 1991, ISBN 0631181776.

LEFEBVRE, Henri. Espaço e Política. Belo Horizonte, UFMG, 2008, ISBN 9788570416872.

LEFEBVRE, Henri. La presencia y la ausencia: contribuiciones a la teoria de las representaciones. Fondo de Cultura Economica, México, 1983, ISBN 9789681677015.

LENCIONI, Sandra. Reconhecendo metrópoles: território e sociedade. In: SILVA, Cátia Antônia da. FREIRE, Désirée Guichard. OLIVEIRA, Floriano José Godinho de. (Orgs.). Metrópole - governo, sociedade e território. Rio de Janeiro: DP\&A: Faperj, 2006. p.41-57.

LENCIONI, Sandra. Redes, Coesão e Fragmentação do território metropolitano. [ONLINE] Vol. XIV, 2010. Disponível em: <http://www.ub.edu/geocrit/sn/sn-331/sn-331-69.htm>

LENCIONI, Sandra. Da cidade e sua região à cidade-região. In: Panorama da Geografia Brasileira I. SILVA, José Bozacchielo da et al (org.). São Paulo: Annablume, 2006. p.65-75.

LENCIONI, Sandra. Metropolização do espaço e a constituição de megarregiões. In: FERREIRA, Alvaro; RUA, João; MATTOS, Regina. (Org). Desafios da metropolização do espaço. Rio de Janeiro, Consequência, 2015.

LENCIONI, Sandra. Urbanização difusa e a constituição de megarregiões: o caso de São Paulo-Rio de Janeiro. In: Revista eletrônica e-metropolis, n-22, ano 6, setembro de 2015b, p.06-15.

PEET, Richard. Imaginários de Desenvolvimento. In: Fernandes, B.M; Marques, M.I; Suzuki, J.C.(Orgs). Geografia Agrária: Teoria e poder. São Paulo, Expressão Popular, 2007. p.19-37.

SANTOS, Milton. A Natureza do Espaço: Técnica e Tempo, Razão e Emoção. 4. ed. 2. reimpr. - São Paulo: Editora da Universidade de São Paulo, 2006, ISBN 9788531407130.

SANTOS, Milton. Espaço e método. 5 ed. São Paulo: EdUSP, 2008, ISBN 9788531410857.

SOUZA, Maria Adélia Aparecida de. Recompondo a história da região metropolitana: processo, teoria e ação. In: Metrópole: governo, sociedade e território. DA SILVA, C. FREIRE, D. OLIVEIRA, F. Rio de Janeiro, DP\&A editora: FAPERJ, 2006, p.27-40.

SOUZA, Marcelo Lopes de. Fobópole. O medo generalizado e a militarização da questão urbana. Rio de Janeiro, Bertrand Brasil, 2008, ISBN 9788528613186. 